\title{
Clinical evaluation with 18 months follow-up of new PTTM enhanced dental implants in maxillo-facial post-oncological patients
}

\author{
Piero Papi, DDS \\ Sara Jamshir, DDS \\ Edoardo Brauner, DDS, PhD \\ Stefano Di Carlo, MD, DDS \\ Antonio Ceci, DDS \\ Luca Piccoli, DDS \\ Giorgio Pompa, MD, DDS
}

Department of Oral and Maxillo-Facial Sciences, "Sapienza" University of Rome, Italy

Corresponding author:

Piero Papi, DDS

Department of Oral and Maxillo-Facial Sciences, "Sapienza" University of Rome, Italy

Via Campania, 6

00161, Rome, Italy

Phone: +393934360087

E-mail: papi.piero@gmail.com

\section{Summary}

Aim. The aim of this study is to present 18 months follow-up results of porous tantalum trabecular metal-enhanced titanium dental implant (PTTM) in implant supported prosthesis in postoncological patients.

Materials and methods. A total of 25 PTTM implants were placed in each jaw of 6 patients that met specific inclusion and exclusion criteria. Resonance Frequency Analysis (RFA) was conducted and Implant stability was recorded in ISQ values (Osstell ISQ, Osstell AB, Goteborg, Sweden) at implant placement and after $2,4,6,12$ and 18 months of functional loading.

Mean bone loss was also evaluated at the same interval of time on each periapical radiographs, bone levels were calculated by measuring the distance from the implant shoulder to the first bone to implant contact.

Results. Cumulative implant survival rate is $100 \%$ $(n=25 / 25)$ to date and mean ISQ values recorded were: $72.14 \pm 5.61$ (range $=50-81$ ) at surgery, $64.39 \pm 8.12$ (range $=44-74$ ) after 2 months, $74.26 \pm 7.14$ (range $=44-74$ ) after 4 months, $76.84 \pm 7.65$ (range $=60$ 83) after 6 months, $78.13 \pm 4.14$ (range $=64-84$ ) after 12 months and $80.22 \pm 6.23$ (range $=68-89$ ) after 18 months of functional loading.

Mean crestal marginal bone loss was $0.19 \pm 0.25$ $\mathrm{mm}$ after 2 months of functional loading on peri- apical radiographs, $0.22 \pm 0.4 \mathrm{~mm}$ at 4 months, $0.3 \pm 0.46 \mathrm{~mm}$ at 6 months, $0.57 \pm 0.62$ at 1 year and $0.64 \pm 0.60 \mathrm{~mm}$ after 18 months.

Conclusions. The results of this study, even if limited by the number of implants placed indicate that PTTM dental implants have a clinical efficacy in prosthetic rehabilitation of post-oncological patients, due to trabecular structure of the porous Ta metal that increases bone-implant connection values.

Key words: trabecular metal, PTTM dental implants, oral cancer, prosthetic rehabilitation.

\section{Introduction}

The treatment for patients with a malignant neoplasia of the oral cavity requires the cooperation of a team of different specialists that follow the patient through the phases of diagnosis, therapy and oral rehabilitation. Ablative surgery is followed by a reconstructive phase after which the patient may need to undergo radiotherapy, a condition that may compromise the success of oral rehabilitation (1-3).

Radiotherapy side effects may include mucositis, xerostomia, damage of the salivary glands and osteoradionecrosis, which could lead the surgeons to proceed to a partial jaw resection (4-6). Chemotherapy side effects are similar to those of radiotherapy and, usually, is possible to perform dental surgery safely before and after chemotherapy if the patient is not further compromised by also undergoing bisphosphonate drug therapy $(7,8)$.

The options for a prosthetic rehabilitation are either the tooth-supported prosthesis or implant-supported overdenture $(4,5)$. However, deformation to the oral structures, by surgical treatments, may prevent a proper osseointegration and result in failure and also conventional tissue-supported restorations may lead to soft tissue management problems (6, 9-13).

Over the years numerous implant surfaces and coatings have been utilized to try to maximize on-growth potential and secondary stability, increasing bone to implant connection values (BIC).

Improvement in surface roughness can be achieved by using Microtextured, Acid Etched, Sand Blasted/Acid Etched, Phosphate Enriched, Hydoxyapatite (HA), Titanium Plasma Spray (TPS), or Nanotexturized implant surfaces.

These surfaces promote the adherence of platelets from the initial clot that releases platelet-derived growth factors (PDGFs), which are chemotactic and 
Clinical evaluation with 18 months follow-up of new PTTM enhanced dental implants in maxillo-facial post-oncological patients

mitogenic for mesenchymal cells and osteoblast progenitor cells (14).

The current implant surface treatment seems to improve osteoblastic activities and reduces peri-implant bone loss, however $100 \%$ Bone to Implant Contact is not achievable because gaps and voids may occur along the surface.

A porous tantalum trabecular metal (PTTM), known commercially as Trabecular Metal Material (Trabecular Metal Technology, Zimmer Inc., Parsippany, NK, USA), used since 1998 in orthopaedic reconstructions, has been adapted for dental implant use to achieve higher BIC values and bone ingrowth (15-18). The aim of this study is to evaluate the clinical efficacy of porous tantalum trabecular metal-enhanced titanium dental implant (PTTM) in implant-supported prosthesis in oral-maxillofacial post-oncological patients.

\section{Materials and methods}

This study was open to all patients that met specific inclusion and exclusion criteria (Tab. 1) and that signed informed consent, according to the World Medical Association's Declaration of Helsinki.

Six patients were enrolled in this study, 4 female $(66,66 \%)$ and 2 male $(33,34 \%)$ with a mean age of $55 \pm 25,45$ years (age range $37-74$ ), they were all postoncologic patients treated for oral cancer (Tab. 2).

The inclusion criteria did not distinguish between patients receiving radiotherapy and non-irradiated patients, when radiotherapy was used it was included in the medical record.

A total of 25 PTTM implants were placed in a period between June and July 2012. Each subject was treated with a number of implants based on their clinical need, bone quantity and quality (Tabs. 3,4 ).

For prophylaxis, one hour before surgery antibiotics were given to the patients: $2 \mathrm{~g}$ of amoxicillin and clavulanic acid (Augmentin ${ }^{\circledR}$, Roche S.p.A., Milan, Italy). Chlorhexidinedigluconate $0,12 \%$ mouth wash (Dentosan ${ }^{\circledR}$ Collutorio Trattamento Mese, Recordati S.p.A., Milano, Italy) was prescribed every day for 7 days after surgery. Patients were provided with written instructions for oral hygiene and were recommended to follow a soft diet for 4 to 5 days post surgery. Written consent for implant treatment was signed by all patients prior to the study. Medical ex-

Table 1. Patient inclusion criteria.

\begin{tabular}{|c|c|}
\hline Inclusion & $\begin{array}{l}\text { Male or female at least } 18 \text { years of age } \\
\text { Benefit from the implant prosthesis } \\
\text { Insertion torque }>35 \mathrm{Ncm}\end{array}$ \\
\hline Exclusion & $\begin{array}{l}\text { Subjects with bruxism or clenching } \\
\text { parafunctional habits } \\
\text { Mental disorders } \\
\text { Uncontrolled systemic disease } \\
\text { Untreated oral pathologies } \\
\text { Pregnancy } \\
\text { Use of Bisphosphonates }\end{array}$ \\
\hline
\end{tabular}

aminations were scheduled respectively 7,14 and 28 days after surgery and then once a month (1/30 days) for the following 18 months.

The definitive restorations were made in a period between 2 and 3 months post surgery.

Resonance Frequency Analysis (RFA) was conducted and Implant stability was recorded in ISQ values (Osstell ISQ, Osstell AB, Goteborg, Sweden) at implant placement and after 2,4,6,12 and 18 months of functional loading.

Standardized (Rinn, Dentsply, York, PA, USA) periapical radiographs were taken for each implant at placement and after 2, 4, 6, 12 and 18 months of functional loading.

Mean bone loss was also evaluated with the same time interval on each periapical radiograph, bone levels were calculated by measuring the distance from the implant shoulder to the first bone to implant contact.

\section{Results}

Cumulative implant survival rate is $100 \%(n=25 / 25)$ to date and all implants had at least 18 months of clinical follow-up after functional loading (Figs. 1, 2, 3). No serious complications or adverse reactions were reported and all implants were stable and well osseointegrated.

Mean ISQ values recorded were: $72.14 \pm 5.61$ at surgery, $64.39 \pm 8.12$ after 2 months, $74.26 \pm 7.14$ after 4 months, $76.84 \pm 7.65$ after 6 months, $78.13 \pm 4.14$ after 12 months and $80.22 \pm 6.23$ after 18 months of functional loading (Tab. 5).

Mean crestal marginal bone loss was $0.19 \pm 0.25 \mathrm{~mm}$ after 2 months of functional loading on periapical radiographs, $0.22 \pm 0.4 \mathrm{~mm}$ at 4 months, $0.3 \pm 0.46$ at 6 months, $0.57 \pm 0.62$ at 1 year and $0.64 \pm 0.60$ after 18 months (Tab. 6).

\section{Discussion}

ISQ results showed an optimal primary stability of the PTTM dental implants thanks to the trabecular structure of the porous Ta metal, which is similar to cancellous bone. High initial ISQ results remained constant over time, while lower initial ISQ values increased more once osseointegration was stabilized (Tab. 5).

Measurements of the distance from the implant shoulder to the first bone to implant contact on periapical radiographs demonstrated a minimal crestal bone loss compared to the conventional titanium alloy dental implants (Tab. 5). PTTM manufacturing process is extremely complex. It utilizes a chemical vapour deposition process (CVD), which deposits elemental tantalum (Ta) onto a substrate and therefore creates a nanotextured surface topography to build the Trabecular Metal Material.

Ta is a transitional metal often extracted from the mineral tantalite, its atomic number is 73 , it's highly biocompatible and corrosion resistant (16). Ta is deposited onto a vitreous carbon skeleton to reproduce the 
Table 2. Patient medical history.

\begin{tabular}{llll}
\hline Patient & Diagnosis & Treatment & Implant placement \\
\hline D.S. & Squamous cell & Anterolateral thigh flap & Six months later two \\
$\begin{array}{l}\text { Woman } \\
52 \text { year old }\end{array}$ & carcinoma of the right & & $\begin{array}{l}\text { submerged PTTM-dental } \\
\text { edge of the tongue }\end{array}$ \\
& & $\begin{array}{l}\text { implants }(4.1 \times 10 \mathrm{~mm}) \\
\text { in the right inferior canine } \\
\text { and premolar locations }\end{array}$ \\
& &
\end{tabular}

$\begin{array}{ll}\text { L.T. } & \text { Unicystic ameloblastor } \\ \text { Woman year old } & \begin{array}{l}\text { of the right mandibular } \\ \text { quadrant }\end{array} \\ & \\ \text { A.L. } & \text { Left floor-of-mouth } \\ \text { Woman } & \text { cancer (FOM) } \\ 74 \text { year old } & \end{array}$

T.G.

Man

56 year old

$\begin{array}{ll}\begin{array}{l}\text { P.D. } \\ \text { Man year old }\end{array} & \begin{array}{l}\text { Osteosarcoma of the } \\ \text { jaw located in the } \\ \text { anterior region of } \\ \text { the maxilla }\end{array} \\ & \begin{array}{ll}\text { C.E. } & \text { Multicystic } \\ \text { Woman year old } & \begin{array}{l}\text { ameloblastoma of the } \\ \text { upper jaw }\end{array}\end{array}\end{array}$

Radical resection of the right posterior mandible and simultaneous reconstruction with iliac crest flap

Partial mandibulectomy from the lower left second premolar to the lower right lateral incisor

END levels I-IV

Simultaneous anterolateral thigh free flap

Radiotherapy

Segmental mandibulectomy in the right posterior mandible Simultaneous pectoralis major flap Radiotherapy

Partial maxillectomy Simultaneous fibula free flap reconstruction

Maxillectomy performed from the right canine to the second left molar Simultaneous fibula free flap reconstruction
Six months later two submerged PTTM-dental implants $(4.1 \times 10 \mathrm{~mm}$, $4.1 \times 11.5 \mathrm{~mm}$ ) in the right posterior mandible

One year after radiotherapy, seven submerged PTTMdental implants in the mandible (2 each $4.1 \mathrm{x}$ $10 \mathrm{~mm}, 2$ each $4.1 \times 11.5$,

two $4.7 \times 11.5 \mathrm{~mm}$ and one $4.1 \times 13 \mathrm{~mm}$ )

One year after radiotherapy, four PTTM- dental implants were placed (2 each $4.1 \mathrm{x}$ $10 \mathrm{~mm}$ and 2 each $4.7 \mathrm{x}$ $11.5 \mathrm{~mm}$ )

Seven months later six submerged PTTM- dental implants (3 each $4.1 \mathrm{x}$ $10 \mathrm{~mm}, 2$ each $4.1 \mathrm{x}$ $11.5 \mathrm{~mm}, 1$ each $4.7 \mathrm{x}$ $11.5 \mathrm{~mm}$ )

Six months later four PTTM- dental implants (2 each $4.1 \times 10 \mathrm{~mm}$, 2 each $4.1 \times 11.5 \mathrm{~mm}$, $4.7 \times 11.5 \mathrm{~mm}$ )

Prosthetic Rehabilitation

Six months later provisional acrylic resin fixed partial denture with a distal cantilever for second premolar occlusion. After one month temporization, a definitive ceramometal restoration

Five months later provisional fixed partial denture, definitive ceramometal restoration one month later

Six months later definitive, screw-retained prosthesis

Tissue-supported overdenture retained by ball abutments after 6 months from implant placement

Five months later fixed implant-supported prosthesis

Six months later a bar-retained overdenture

Table 4. Treatment sites.

Table 3. Trabecular metal dental implants inserted.

\begin{tabular}{llll}
\hline Lenghts $(\mathrm{mm})$ & \multicolumn{3}{l}{ Diameters $(\mathrm{mm}) \varnothing$} \\
& $4,1 \mathrm{~mm}$ & $4,7 \mathrm{~mm}$ & Implants \\
\hline $10 \mathrm{~mm}$ & 12 & 0 & 12 \\
$11,5 \mathrm{~mm}$ & 5 & 6 & 12 \\
$13 \mathrm{~mm}$ & 1 & 0 & 1 \\
\hline
\end{tabular}

trabecular bone structure and its properties. Prof. Branemark was the first to use Ta in the implantology field however due to its production costs and difficulty of extraction it was quickly abandoned.

Trabecular Metal material is a porous biomaterial with up to $80 \%$ interconnected porosity. It has an opencell three-dimensional dodecahedrical shape, that resembles trabecular bone and its 12 interconnecting hexagonal pores. These pores have an average size

\begin{tabular}{lll}
\hline Maxillary locations & Lateral Incisor & 1 \\
& Canine & 1 \\
& First premolar & 1 \\
& Second premolar & 1 \\
& First molar & 6 \\
& Second molar & 4 \\
Mandibular locations & Lateral Incisor & 1 \\
& Canine & 5 \\
& First premolar & 1 \\
& Second premolar & 2 \\
& First molar & 1 \\
& Second molar & 1 \\
\hline
\end{tabular}

of $440 \mu \mathrm{m}$ to allow vascularized bone ingrowth, which requires a minimum size of $300 \mu \mathrm{m}$ (19).

PTTM enhanced titanium dental implants (Trabecular 
Clinical evaluation with 18 months follow-up of new PTTM enhanced dental implants in maxillo-facial post-oncological patients

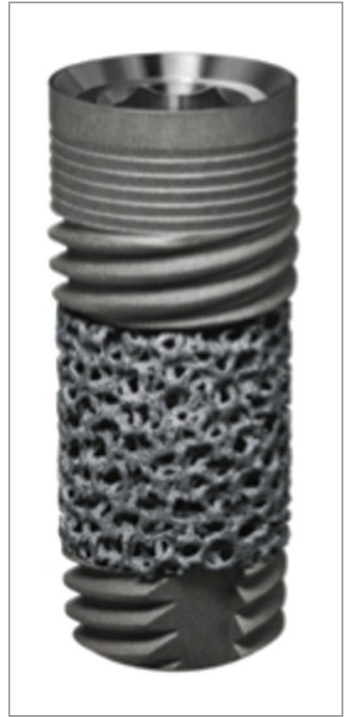

Figure 1. Trabecular metal dental implant.

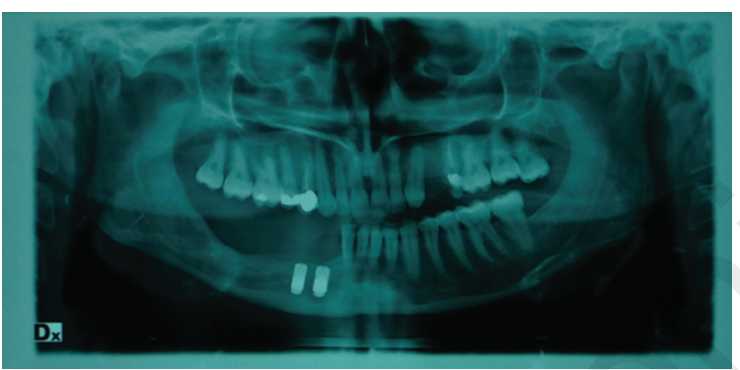

Figure 3. Post-surgical orthopantomography.

Table 6. Crestal bone loss $(\mathrm{mm})$.

\begin{tabular}{llll}
\hline Interval & Measurement Location & Mean Bone level $(\mathrm{mm})$ & Range \\
\hline Surgery & Mesial & $0.5 \pm 0.48$ & $0.07-1.8$ \\
& Distal & $0.62 \pm 0.70$ & $0.03-2.3$ \\
& Average & $0.56 \pm 0.48$ & $0.03-2.3$ \\
\multirow{3}{*}{ Months } & Bone loss Mesial & $0.21 \pm 0.46$ & $-0.65-1.1$ \\
& Bone loss Distal & $0.18 \pm 0.23$ & $-0.48-0.94$ \\
4 Months & Bone loss Average & $0.19 \pm 0.25$ & $-0.48-1.1$ \\
& Bone loss Mesial & $0.24 \pm 0.48$ & $-0.9-1.4$ \\
& Bone loss Distal & $0.20 \pm 0.22$ & $-0.8-1.5$ \\
6 Months & Bone loss Average & $0.22 \pm 0.4$ & $-0.8-1.5$ \\
& Bone loss Mesial & $0.28 \pm 0.49$ & $-1.06-1.2$ \\
1 Year & Bone loss Distal & $0.33 \pm 0.48$ & $-0.8-0.96$ \\
& Bone loss Average & $0.3 \pm 0.46$ & $-0.8-1.2$ \\
18 Months & Bone loss Mesial & $0.55 \pm 0.71$ & $-0.78-2.09$ \\
& Bone loss Distal & $0.59 \pm 0.53$ & $-0.41-1.89$ \\
& Bone loss Average & $0.57 \pm 0.62$ & $-0.78-2.09$ \\
\hline
\end{tabular}

Metal Dental Implant, Zimmer Dental Inc., Carlsbad, CA, USA) were introduced in 2012. They are composed of a PTTM material midsection added to a tita-
Table 5. Resonance frequency Analysis (RFA).

\begin{tabular}{lll}
\hline Interval & ISQ Values & Range \\
\hline Surgery & $72.14 \pm 5.61$ & $50-81$ \\
2 Months & $64.39 \pm 8.12$ & $44-74$ \\
4 Months & $74.26 \pm 7.14$ & $52-80$ \\
6 Months & $76.84 \pm 7.65$ & $60-83$ \\
1 Year & $78.13 \pm 4.14$ & $64-84$ \\
18 Months & $80.22 \pm 6.23$ & $68-89$ \\
\hline
\end{tabular}

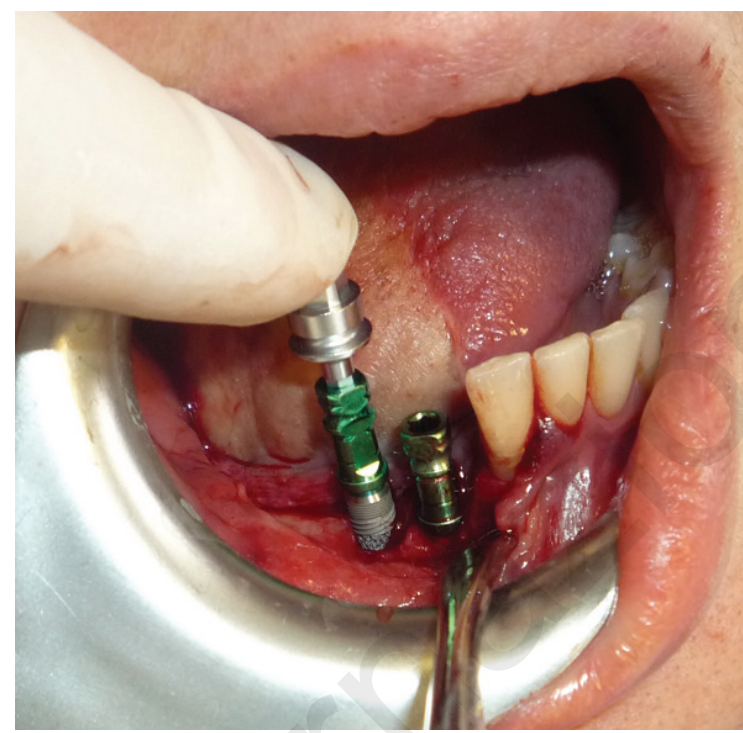

Figure 2. Trabecular metal dental implants placements.

nium multi threaded self-tapping endosseous dental implant (Tapered Screw-Vent Implant, Zimmer Dental Inc., Carlsbad, CA, USA). These dental implants con- 
sist of a titanium cervical and internal core section covered by a trabecular metal shell and joined by a $\mathrm{Ti}$ apical section. The tapered titanium alloy (Ti-6Al-4V grade 5) used in the cervical and apical sections provides the strength of traditional dental implants, while titanium alloy and PTTM components are produced separately and laser welded.

This structure allows to achieve Osseoincorporation, a combination of osseointegration and bone in growth into the porous structure as demonstrated by in vivo (2022) and in vitro (23) studies and by histologic testing in transcortical canine $(24,25)$ and human $(26)$ models. With respect to the conventional titanium alloy implants (27-31), the Secondary Stability is increased in PTTM dental implants, which leads to achieve better results in critical situations such as maxillofacial trauma, cleft and lip palate $(32,33)$ and post-oncologic patients.

This study represents the first clinical trial of PTTM dental implants in post-oncological patients and our preliminary results indicate that PTTM dental implants could have a clinical efficacy in prosthetic rehabilitation of these patients.

\section{References}

1. Chan MF, Hayter JP, Cawood JI, Howell RA. Oral rehabilitation with implant-retained prostheses following ablative surgery and reconstruction with free flaps. Int J Oral Maxillofacial Implants. 1997;12:820-827.

2. Chang YM, Santamaria E, Wei FC, Chen HC, Chan CP, Shen YF, Hou SP. Primary insertion of osseointegrated dental implants into fibula osteoseptocutaneous free flap for mandible reconstruction. Plast Reconstr Surg. 1998;102:680-687.

3. Chiapasco M, Lang NL, Karring T, LindheJ. Quintessence Books. Berlin: 1999. Implants for patients with maxillofacial defect and following irradiation: Proceedings III European Workshop on Periodontology. pp. 557-607.

4. Brauner E, Valentini V, Jamshir S, Battisti A, Guarino G, Cassoni A, Gaimari G, Fadda MT, Di Carlo S, Pompa G. Two clinical cases of prosthetical rehabilitation after a tumor of the upper maxilla. Eur Rev Med Pharmacol Sci. 2012; Vol. 16 - N. 13:1882-1890.

5. Brauner E, Valentini V, Guarino G, Cassoni A, Jamshir S, Minasi R, Fadda MT, Pagnoni M, Pompa G. Osteoradionecrosis of a mandible: A case report of implant-supported rehabilitation. European Journal of Inflammation. 2013; Volume 11, Issue 2:565-571.

6. Chiapasco M, Abati S, Ramundo G, Rossi A, Romeo E, Vogel $\mathrm{G}$. Behavior of implants in bone grafts or free flaps after tumor resection. Clin Oral Impl Res. 2000;11:66-75.

7. Periodontal considerations in the management of the cancer patients. Committee on research, science and therapy of the American Academy of Periodontology. J Periodontol. 1997;68:791-801.

8. Chaveli López B, Gavaldá Esteve C, Sarrión Pérez MG. Dental treatment considerations in the chemotherapy patient. $J$ Clin Exp Dent. 2011;3:e31-e42.

9. Garrett N, Roumanas ED, Blackwell KE, Freymiller E, Abemayor E, Wong WK, Gerratt B, Berke G, Beumer J 3rd, Kapur KK. Efficacy of conventional and implant-supported mandibular resection prostheses: study overview and treatment outcomes. J Prosthet Dent. 2006 Jul;96(1):13-24.

10. Goga D, et al. Microvascular mandibular reconstruction and implantology. A Study of the stability of long term results, apro- pos of 2 cases followed for 8 years. Rev Somatol Chir Maxillofac. 1999;(5-6):231-234.

11. Goiato MC, Ribeiro AB, Dreifus Marinho ML. Surgical and prosthetic rehabilitation of patients with hemimandibular defect. J Craniofac Surg. 2009 Nov;20(6):2163-7. Review.

12. Hotz G. Reconstruction of mandibular discontinuity defect with delayed nonvascularized free iliac crest bone graft and endosseous implants: a clinical report. Prosthett. 1996;76:350355.

13. Kovacs AF. Influence of the prosthetic restoration modality on bone loss around dental implants placed in vascularised iliac bone grafts for mandibular reconstruction. Otolaryngo Head Neck Surg. 2000;123(5):598-602.

14. Pompa G, Bignozzi I, Cristalli MP, Quaranta A, Di Carlo S. Bisphosphonates and Osteonecrosis of the jaw: the oral surgeon's perspective. European Journal of Inflammation. 2012;10(1):11-23.

15. Pompa V, Brauner E, Bresadola L, Di Carlo S, Valentini V, Pompa G. Treatment of facial vascular malformations with embolization and surgical resection. Eur Rev Med Pharmaco Sci. 2012 Mar;16(3):407-13.

16. Miyazaki T, Kim HM, Kokubo T, Ohtsuki C, Kato H, Nakamura T. Mechanism of bonelike apatite formation on bioactive tantalum metal in a simulated body fluid. Biomaterials. 2002;23:827-832.

17. Bobyn JD, Poggie RA, Krygier JJ, et al. Clinical validation of a structural porous tantalum biomaterial for adult reconstruction. J Bone Joint Surg Am. 2004;86-A (Suppl 2):123-129.

18. Cohen R. A porous tantalum trabecular metal: basic science. Am J Orthop. 2002;31:216-217.

19. Hacking SA, Bobyn JD, Toh K, Tanzer M, Krygier JJ. Fibrous tissue ingrowth and attachment to porous tantalum. J Biomed Mater Res. 2000;52:631-638.

20. Harrison AK, Gioe TJ, Simonelli C, Tatman PJ, Schoeller MC Do porous tantalum implants help preserve bone? Evaluation of tibial bone density surrounding tantalum tibial implants in TKA. Clin Orthop Relat Res. 2010; 468:2739-2745.

21. Karageorgiou V, Kaplan D. Porosity of 3D Biomaterial Scaffolds and Osteogenesis. Biomaterials. 2005; 26(27):5474-91.

22. Bencharit S, Byrd WC, Altarawneh S, et al. Development and applications of porous tantalum trabecular metal-enhanced titanium dental implants. Clin Implant Dent Relat Res. 2013. DOI: $10.1111 / C I D .12059$

23. Schelee M, Van der Schoor P, Wen HB, et al. European Multicenter studies of a porous tantalum-titanium implant: one year interim results. Presented at the 28th Annual Meeting of the Academy of Osteointegration. 2013, Tampa, Florida.

24. Schlee M, Van der Schoor P, Van der Schoor ARM. Immediate loading of Trabecular Metal-enhanced titanium dental implants: interim results from an international proof-of-principle study. Clin Implant Dent Relat Res. 2013.

25. Collins M, Bassett J, Wen HB, Gervais C, Lomicka M, Papanicolaou S. Zimmer ${ }^{\circledR}$ Trabecular Metal ${ }^{\mathrm{TM}}$ Dental Implant Research: A Brief Overview. Zimmer Clinical Paper. 2012; $\checkmark$ no 9 .

26. Kim DG, Huja SS, Ching Tee B, et al. Evaluation of Trabecular Metal dental implants in a canine model. Presented at the 19th Annual Scientific Meeting of the European Association for Osseointegration, Glasgow, Scotland, UK. 2010.

27. Kim DG, Huja SS, Ching Tee B, et al. Bone ingrowth and initial stability of titanium and porous tantalum dental implants: a pilot canine study. Implant Dent. 2013

28. Clemente de Arriba C, Bradbury K, Alobera Gracia MA, del Canto M, Wen H, Carlsbad CA. Osseoincorporation of Porous Tantalum Cylinders in Human Subjects: Interim Results. Presented at the 28th Annual Meeting of the Academy of Osteointegration. 2013, Tampa, Florida.

29. Battula S, Papanicolaou S, Lee J, Wen H, Carlsbad CA. Eval- 
Clinical evaluation with 18 months follow-up of new PTTM enhanced dental implants in maxillo-facial post-oncological patients

uation of Trabecular Metal Material Dental Implant Assembly in a Canine Periimplantitis Model. Presented at the 28th Annual Meeting of the Academy of Osteointegration. 2013, Tampa, Florida.

30. Battula S, Papanicolaou S, Lomicka M, Wen HB, Carlsbad CA. Mechanical and interfacial strenght evaluations of a trabecular metal dental implant assembly. Presented at the 27th Annual Meeting of the Academy of Osteointegration. 2012. Phoenix, Arizona.

31. Battula S, Papanicolaou S, Wen HB, Collins M, Carlsbad CA.
Evaluation of a Trabecular Metal dental implant design for primary stability. Structural integrity and abrasion. Presented at the 27th Annual Meeting of the Academy of Osteointegration. 2012, Phoenix, Arizona.

32. Scopelliti D, Fatone FM, Cipriani O, Papi P. Simultaneous options for cleft secondary deforities. Ann Maxillofac Surg. 2013 Jul;3(2):173-7.

33. Scopelliti D, Cipriani O, Fatone FM, Papi P, Amodeo G. Cleft palate in Williams syndrome: a case report. Ann Maxillofac Surg. 2013 Jan;3(1):84-6. 